\title{
Loss of Feedback Inhibition via D2 Autoreceptors Enhances Acquisition of Cocaine Taking and Reactivity to Drug-Paired
} Cues

\author{
Kathryn B Holroyd', Martin F Adrover', Robert L Fuino', Roland Bock', Alanna R Kaplan', \\ Christina M Gremel' ${ }^{2}$, Marcelo Rubinstein ${ }^{3,4}$ and Veronica A Alvarez, ${ }^{*}$, \\ 'Section on Neuronal Structure, National Institute on Alcohol Abuse and Alcoholism, National Institute of Health, Bethesda, MD, USA; \\ ${ }^{2}$ Laboratory for Integrative Neuroscience, National Institute on Alcohol Abuse and Alcoholism, National Institute of Health, Bethesda, MD, USA; \\ ${ }^{3}$ Instituto de Investigaciones en Ingeniería Genética y Biología Molecular, Consejo Nacional de Investigaciones Científicas y Técnicas, Buenos Aires, \\ Argentina; ${ }^{4}$ Facultad de Ciencias Exactas y Naturales, Universidad de Buenos Aires, Buenos Aires, Argentina
}

\begin{abstract}
A prominent aspect of drug addiction is the ability of drug-associated cues to elicit craving and facilitate relapse. Understanding the factors that regulate cue reactivity will be vital for improving treatment of addictive disorders. Low availability of dopamine (DA) D2 receptors (D2Rs) in the striatum is associated with high cocaine intake and compulsive use. However, the role of D2Rs of nonstriatal origin in cocaine seeking and taking behavior and cue reactivity is less understood and possibly underestimated. D2Rs expressed by midbrain DA neurons function as autoreceptors, exerting inhibitory feedback on DA synthesis and release. Here, we show that selective loss of D2 autoreceptors impairs the feedback inhibition of DA release and amplifies the effect of cocaine on DA transmission in the nucleus accumbens (NAc) in vitro. Mice lacking D2 autoreceptors acquire a cued-operant self-administration task for cocaine faster than littermate control mice but acquire similarly for a natural reward. Furthermore, although mice lacking D2 autoreceptors were able to extinguish self-administration behavior in the absence of cocaine and paired cues, they exhibited perseverative responding when cocainepaired cues were present. This enhanced cue reactivity was selective for cocaine and was not seen during extinction of sucrose selfadministration. We conclude that low levels of D2 autoreceptors enhance the salience of cocaine-paired cues and can contribute to the vulnerability for cocaine use and relapse.

Neuropsychopharmacology (20I5) 40, I495-1509; doi:I0.1038/npp.2014.336; published online 21 January 2015
\end{abstract}

\section{INTRODUCTION}

A prominent aspect of drug addiction is the ability of drugassociated cues to elicit craving and facilitate relapse (Ehrman et al, 1992). In human drug abusers, the strength of craving correlates with the magnitude of increase in dopamine (DA) in the striatum, and the presentation of drug-associated cues, such as drug paraphernalia, can by itself trigger large increases in DA (Volkow et al, 2006; Wong et al, 2006). Understanding how drug-associated cues contribute so strongly to dependence and relapse is vital for a comprehensive understanding of addiction and for improving treatment.

Low availability of striatal D2 receptors (D2Rs) is found in human cocaine abusers (Volkow et al, 2009; Volkow et al,

*Correspondence: Dr VA Alvarez, Section on Neuronal Structure, National Institute on Alcohol Abuse and Alcoholism, National Institute of Health, 5625 Fishers Lane, MSC 94II, Bethesda, MD 20892, USA, Tel: + 30 | 443 7695, Fax: + 30 | 4808035 ,

E-mail: alvarezva@mail.nih.gov

Received 15 August 2014; revised 15 December 2014; accepted 17 December 2014; accepted article preview online 30 December 2014
1997) and is associated with high cocaine intake in primates (Nader et al, 2006) and vulnerability to compulsive cocaine use in rodents (Belin et al, 2008; Dalley et al, 2007). However, the specific roles of D2Rs on striatal vs nonstriatal neurons in reward-motivated behaviors, including cocaine seeking, are still unclear. A recent study found low levels of D2 mRNA in the VTA and the SNc of highly impulsive animals, suggesting that impulsivity is linked to lower levels of both striatal D2 receptors and autoreceptors (Besson et al, 2013). Other studies in humans also found that low levels of midbrain D2R availability correlate with increased subjective responses to amphetamine and impulsivity traits, two strong predictors for developing substance abuse (Buckholtz et al, 2010; Zald et al, 2008). Thus, these studies further implicate the level of D2 autoreceptors as an important factor in regulating drug-taking behavior.

D2Rs expressed in midbrain DA neurons, known as autoreceptors, are localized on dendrites within the midbrain and on presynaptic terminals of axonal projections to the nucleus accumbens (NAc), cortex, and striatum (Ford, 2014). D2 autoreceptors are thought to mediate inhibitory feedback control over DA neuron excitability, DA synthesis, and DA release (Ford, 2014; Rice et al, 2011). We recently 
generated conditional mutant mice selectively lacking D2 autoreceptors (autoDrd2KO) but with normal mRNA levels for $\mathrm{D} 2 \mathrm{R}$ in the striatum (Bello et al, 2011). AutoDrd2KO mice show increased DA synthesis and release and have enhanced locomotor activity. The locomotor response to a single noncontingent cocaine injection is also enhanced in autoDrd2KO mice, indicating a role for D2 autoreceptors in regulating the psychomotor response to cocaine. It is still unknown, however, whether D2 autoreceptors modulate the behavioral response to contingent cocaine exposure.

In this study, we examine the ability of drug-paired cues to act as secondary reinforcers and incentivize behaviors including cocaine seeking, extinction, and reinstatement in a rodent model. We show that mice lacking D2 autoreceptors acquire cued-operant self-administration for cocaine faster than littermate control mice, but similarly for sucrose. The response to cocaine in vitro is enhanced in autoDrd2 $\mathrm{KO}$ mice, as well as the behavioral reactivity to drug-paired cues. This study provides critical evidence that the feedback inhibition mediated by D2 autoreceptors acts to limit acquisition of cocaine-taking behavior and the incentive salience of rewardassociated cues. Furthermore, the results show that selective manipulation of D2R levels expressed by nonstriatal neurons causes phenotypic changes in drug-related behaviors that have been associated with human cocaine abusers.

\section{MATERIALS AND METHODS}

\section{Animals and Housing}

Experiments were performed in accordance with guidelines from the NIAAA animal care and use committee. AutoDrd2KO mice were generated by crossing $\operatorname{Drd} 2^{\text {loxP/loxP }}\left(\operatorname{Drd2}^{\text {tm1.Mrub }}\right)$ mice and DAT $T^{+/ \text {IRES-CRE }}$ (B6.SJL-Slc6a3 ${ }^{\text {tm1.1(cre)Bkmn }}$ ) mice as described previously (Bello et al, 2011). This cross-generated autoDrd2KO $\left(\right.$ Drd2 $\left.2^{\text {loxP/loxP }} ; D A T^{+ \text {IIRES-CRE }}\right)$ and Drd2 $2^{\text {loxP/loxP }}$ littermates in equal proportions. For self-administration experiments, littermate autoDrd2KO and $\operatorname{Drd} 2^{\operatorname{lox} P / \operatorname{lox} P}$ mice were trained in parallel in order to compare behavioral phenotypes between littermates. The use of $D A T^{+/ \text {IRES-CRE }}$ as control for the behavioral experiments was not appropriate as these mice are not autoDrd2KO littermates and could introduce other confounding factors such as different background strain, difference in rearing, and so on. Before surgery, mice were group housed and after surgery, mice were individually housed on reversed light cycle (lights off at 0630$1830 \mathrm{~h})$. For analysis of CRE recombinase expression, the fluorescent CRE reporter mouse line B5.Cg-Gt(ROSA)26Sortm14(CAG-tdTomato)Hze (Madisen et al, 2010) was crossed with autoDrd2KO mice and revealed the expected pattern of Cre recombination restricted to DA neurons throughout the brain (Figure 1a-d). For fast-scan cyclic voltammetry (FSCV), mice were group housed on a regular $12 \mathrm{~h}$ light/ dark cycle (lights on at 0630-1830 h). Food and water were always provided ad libitum, except for experiment E.

\section{Genotyping}

Primer sets for tail-tip PCR were as follows: $\operatorname{Drd} 2^{\text {loxP }}$ allele (5'-GCTTCACAGTGTGCTGCCTA- $3^{\prime}$ and $5^{\prime}$-CCATTGCTGC CTCTACCAAG- $\left.3^{\prime}\right)$; CRE recombinase ( $5^{\prime}$-AAAATTTGCCT
GCATTACCG- $3^{\prime}$ and $5^{\prime}$-GCATAACCAGTGAAACAGCATT GCTG-3'), or DAT ${ }^{+/ I R E S-C R E}$-specific primers $\left(5^{\prime}\right.$-TGGCTGTT GGTGTAAAGTGG-3'， 5'-GGACAGGGACATGGTTGACT-3', and $5^{\prime}$-CCAAAAGACGGCAATATGGT-3').

\section{Intracranial Viral Gene Transfer}

AutoDrd2KO and control DAT $T^{+/ I R E S-C R E}$ mice (5-6 weeks old) were anesthetized with isoflurane and placed on a stereotaxic device. Bilateral injections ( $300 \mathrm{nl}$ per site at $100 \mathrm{nl} / \mathrm{min}$ ) of AAV-EF1a-DIO-ChR2(H134R)-EYFP (serotype 5 , titer $=4 \times 10^{12} \mathrm{VM} / \mathrm{ml}$, UNC Vector Core) were performed into the ventral tegmental area (VTA, AP: $-3.25 \mathrm{~mm}$; ML: $\pm 0.40 \mathrm{~mm}$; DV: $-4.50 \mathrm{~mm}$; from Bregma) as described previously (Adrover et al, 2014). Recordings were carried out $41 \pm 7$ days after surgery in order to allow for sufficient levels of ChR2 expression.

\section{Fast-Scan Cyclic Voltammetry}

AutoDrd2KO mice and control $D A T^{+/ \text {IRES-CRE }}$ mice were used to characterize the DA transmission. DAT $T^{+/ I R E S-C R E}$ controls were used because of the need for Cre-dependent expression of ChR2 in DA neurons. Mice were anesthetized with isoflurane and killed by decapitation at least 4 weeks after surgery. Brains were quickly removed, mounted, and sliced parasagittal with vibratome (VT-1200S Leica) in icecold cutting solution containing (in $\mathrm{mM}$ ) 225 sucrose, 13.9 $\mathrm{NaCl}, 26.2 \mathrm{NaHCO}_{3}, 1 \mathrm{NaH}_{2} \mathrm{PO}_{4}, 1.25$ glucose, $2.5 \mathrm{KCl}, 0.1$ $\mathrm{CaCl}_{2}, 4.9 \mathrm{MgCl}_{2}$, and 3 kynurenic acid. Slices $(240 \mu \mathrm{m})$ were kept for $20 \mathrm{~min}$ at $33^{\circ} \mathrm{C}$ in artificial cerebrospinal fluid (ACSF) containing (in $\mathrm{mM}$ ) $124 \mathrm{NaCl}, 1 \mathrm{NaH}_{2} \mathrm{PO}_{4}, 2.5 \mathrm{KCl}$, $1.3 \mathrm{MgCl}_{2}, 2.5 \mathrm{CaCl}_{2}, 20$ glucose, $26.2 \mathrm{NaHCO}_{3}$, and 0.4 ascorbic acid, and later maintained in the dark at room temperature. Slices were placed in a submerged chamber perfused at $2 \mathrm{ml} / \mathrm{min}$ with ACSF containing D-serine $(10 \mu \mathrm{M})$ and gabazine $(5 \mu \mathrm{M})$ at $32{ }^{\circ} \mathrm{C}$ using an in-line heater. Carbonfiber microelectrodes were prepared with T650 fibers $(6 \mu \mathrm{m}$ diameter, $\sim 150 \mu \mathrm{m}$ of exposed fiber) inserted into a glass pipette and held at $-0.4 \mathrm{~V}$ versus $\mathrm{Ag} / \mathrm{AgCl}$. A triangular voltage ramp $(-0.4$ to +1.2 and back to $-0.4 \mathrm{~V}$ at $400 \mathrm{~V} / \mathrm{s})$ was delivered every $100 \mathrm{~ms}$. DA concentration transients were evoked every 2 min by alternating electrical and optogenetic stimulation in the NAc shell. For electrical stimulation, a glass pipette filled with ACSF was placed $\sim 100 \mu \mathrm{m}$ from the carbon fiber and a pulse $(100-250 \mu \mathrm{A}, 0.2 \mathrm{~ms})$ was delivered. For optogenetic stimulation, an optic fiber (multimode, $200 \mu \mathrm{m})$ connected to a diode pumped blue laser $(473 \mathrm{~nm}$, $25 \mathrm{~mW}$, CrystaLaser) was placed within $250 \mu \mathrm{m}$ of the carbon fiber. For some experiments, light pulses $(0.2 \mathrm{~ms}, \sim 700 \mu \mathrm{W})$ were delivered every $2 \mathrm{~min}$. Data were collected with a modified headstage (CB-7B/EC retrofit with $5 \mathrm{M} \Omega$ resistor) using Multiclamp 700B amplifier (Molecular Devices), lowpass filtered at $10 \mathrm{kHz}$, and digitized at $100 \mathrm{kHz}$ using pClamp10 software. For analysis, baseline voltammograms before stimulation were averaged and subtracted from the voltammograms during and after stimulation.

\section{Operant Intravenous Cocaine Self-Administration}

Surgery. Male mice were implanted with an indwelling catheter (CamCath) in the right jugular vein as described 

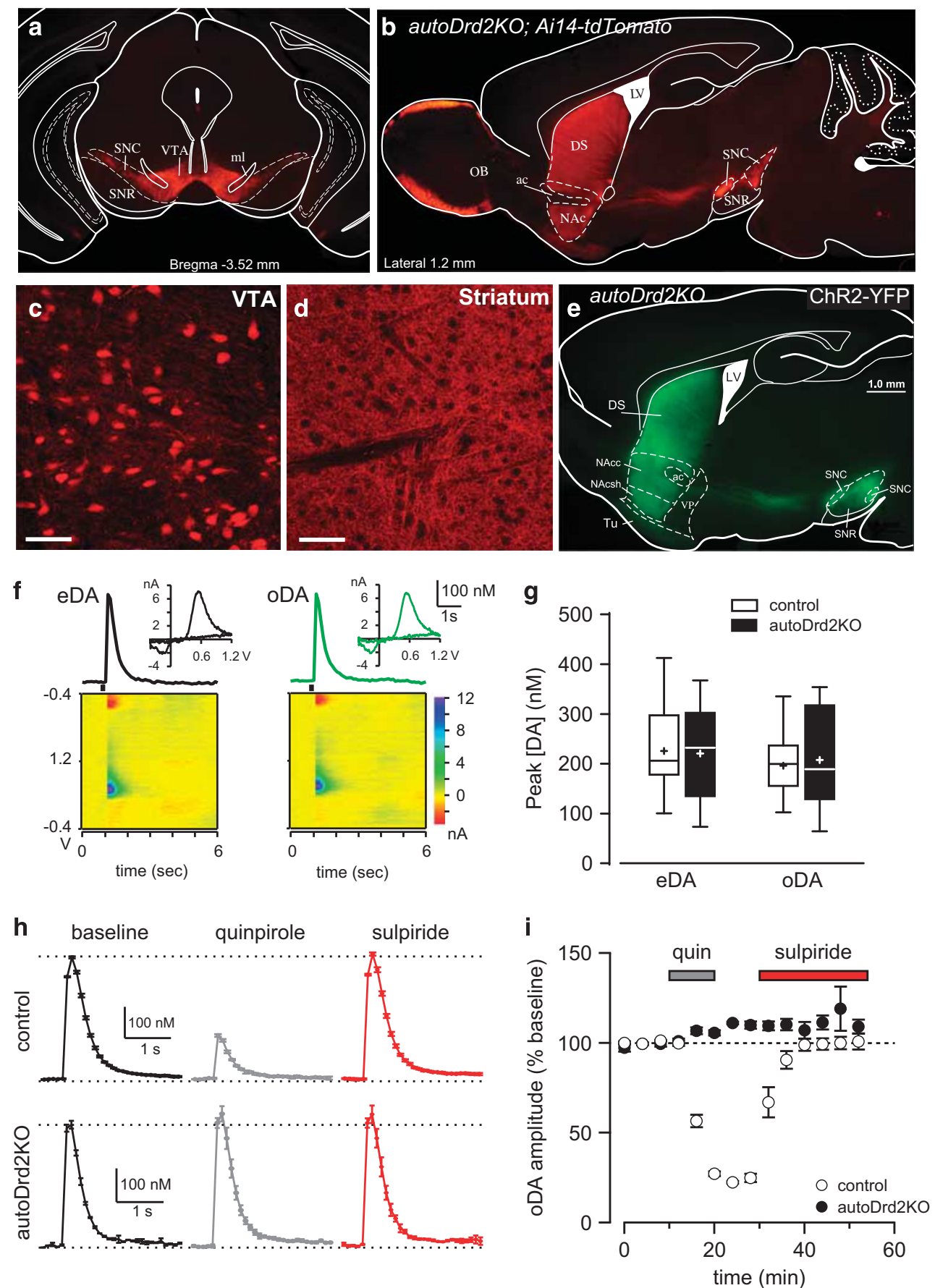

Figure I Selective pattern of Cre recombinase expression and loss of D2 autoreceptors in autoDrd2KO mice. (a, b) Cre recombinase expression revealed with the fluorescent reporter tdTomato shown in coronal (a) and sagittal (b) brain sections of autoDrd2KO mice overlaid onto mouse brain atlas outline (Franklin and Paxinos, third edition, 2007). Note fluorescence in the ventral tegmental area (VTA), susbantia nigra compacta (SNC), and projections to the NAc and dorsal striatum (DS). In addition, Cre-expressing neurons were seen in the olfactory bulb (OB). SNR, substantia nigra reticulata; ml, medial lemniscus; ac, anterior commissure. Scale bars $=1 \mathrm{~mm}$. (c, d) Confocal images showing fluorescently labeled neuronal cell bodies in VTA (c) and axonal projection in the striatum (d). Scale bars $=50 \mu \mathrm{m}$. (e) Channelrhodopsin-2 tagged eYFP expression in midbrain DA neurons and their axonal projections to NAc shell (NAcsh), core (NAcc), and dorsal striatum (DS) shown in sagittal brain section of autoDrd2 mice overlaid onto atlas outline. VP, ventral pallidum; LV, lateral ventricle; Tu, olfactory tubercle. (f, top) Representative eDA and oDA transients in NAc shell of autoDrd2KO mice. (f, bottom) Color plots showing voltammetric current (color scale) over time as a function of the applied potential $(\mathrm{V})$. Inset shows current vs voltage plot of DA signals showing characteristic oxidation and reduction peaks. (g) Box-and-whisker plot of peak concentration for eDA and oDA transients recorded in control mice (open) and autoDrd2KO mice (solid): box = 25-75 percentiles, whiskers = minimum-maximum, line = median, cross=mean. (h) Traces showing average oDA transients before and after application of the D2-like agonist quinpirole (I $\mu \mathrm{M}$, gray) and after subsequent application of the D2R antagonist sulpiride ( $\mu \mathrm{M}$, red) in control (top) and autoDRD2KO mice (bottom). (i) Quinpirole ( I $\mu \mathrm{M}$ ) inhibit oDA transient in control mice (open), whereas it had no effect on autoDrd2KO (filled) mice. Sulpiride $(\mathrm{I} \mu \mathrm{M})$ reversed the inhibition in control mice and had no effect on autoDrd2KO mice. 
previously (Bock et al, 2013). Briefly, an incision was made on the neck to expose and isolate the right jugular vein. The catheter was inserted in the vein through a hole punctured with a $27 \mathrm{G}$ needle tip and, once blood was drawn to confirm correct placement in the vein, the catheter was fixed in place with sutures. The catheter was fed subcutaneously to an opening in the midscapular section where the catheter port was fixed with sutures. Mice were allowed to recover for 5-7 days before behavioral testing and received oral antibiotics (Trimethoprim Sulfamethoxazole, $0.72 \mathrm{mg} / \mathrm{ml}$ in drinking water) during this time. An average of $88 \%$ of animals survived surgery and started behavior testing. Catheters were maintained by daily flushes with heparinized saline $(100 \mathrm{U} / \mathrm{ml})$ and patency was determined every 7-10 days by an anesthetic cocktail $(1.5 \mathrm{mg} / \mathrm{kg}$ ketamine, $0.75 \mathrm{mg} / \mathrm{ml}$ midazepan). Patency was determined by a loss of righting reflex within $2 \mathrm{~s}$ for the first 2 weeks after surgery, and within $10 \mathrm{~s}$ for weeks 3-4 after surgery. Mice that failed patency at any point during training $(\sim 19 \%)$ were removed from the study. Self-administration experiments were performed during the dark phase of the light cycle in modified operant boxes (MedAssociates; size $=6 \mathrm{~cm} \mathrm{~W} \times 17$ $\mathrm{cm} \mathrm{L} \times 13 \mathrm{~cm} \mathrm{H}$ ) equipped with ventilator fan, house light (OFF), drug infusion pump (speed $6 \mu \mathrm{l} / \mathrm{s}$ ), and a one channel fluid swivel mounted on a counterbalanced arm. Two nose-poke holes, one active and the other inactive, were located on each side of the chamber. The box contained two stimulus lights: a drug availability light located above the active nose-poke hole that remained on whenever a cocaine reinforcer could be obtained, known as the discriminative stimulus (DS), and a cue light located in the active nose-poke hole that turned on in response to a nose-poke and remained on for $4 \mathrm{~s}$ while the cocaine infusion was delivered, known as the conditioned stimulus (CS). Every session was initiated with an infusion of one unit dose of cocaine, or saline in the case of extinction and reinstatement. Data were collected with MedPC software and analyzed using Igor Pro.

Training sessions. Operant-naive and cocaine-naive mice (autoDrd2KO and control littermate $\operatorname{Drd} 2^{\operatorname{loxP} / l o x P}$, males, age $=44.7 \pm 0.6$ days) were trained to poke in a nose-hole to earn a cocaine infusion $(1 \mathrm{mg} / \mathrm{kg})$ as a reinforcer in daily sessions 6 days a week. This dose was chosen based on previous cocaine self-administration studies in mice (Caine et al, 2002, 2007; Thomsen et al, 2009a; Zhang et al, 2006). Pokes in the active hole triggered delivery of a single intravenous cocaine infusion $(1 \mathrm{mg} / \mathrm{kg}, 12-18 \mu \mathrm{l}$ over $2-3 \mathrm{~s}$ based on mouse weight) paired with CS followed by a $10-s$ timeout where no drug could be obtained and the drug availability light (DS) was turned off. Pokes in the inactive hole had no consequence but were recorded. Sessions lasted $2 \mathrm{~h}$ with the exception of the first three sessions that were longer $(6 \mathrm{~h})$ in order to facilitate learning. Because of time and space constraints, $4 \mathrm{Drd} 2^{\operatorname{loxP} / \operatorname{lox} P}$ and 5 autoDrd2KO mice received three long sessions of $3 \mathrm{~h}$ and $40 \mathrm{~min}$, instead of $6 \mathrm{~h}$, and hence data from these mice were only used for the extinction and progressive responding analysis (after meeting acquisition criteria as outlined below) and excluded from the training curves. Criteria for acquisition of self-administration behavior was an average of $3: 1$ ratio of active to inactive pokes and at least 10 cocaine reinforcers per session, similar to criteria used by other studies of intravenous cocaine self-administration in rodents (RuizDurantez et al, 2006; Thomsen and Caine, 2005a; Thomsen et al, 2009a). In order to meet criteria, mice should reach these levels for 4 consecutive sessions (if a mouse reached these values during one session but it was followed by more than one session in which the values were not reached, the mouse was not considered to have met criteria yet). A few animals (8\%: 4 Drd2 $2^{\text {loxP/loxP }}$ and 1 autoDrd2KO) were excluded from the study because of extremely low responding throughout seven consecutive sessions $(<10$ pokes total).

Progressive responding session. A single progressive responding session was performed in all mice that met criteria for acquisition and had a patent catheter the day before testing. In this session the number of nose pokes required to obtain a cocaine reinforcer increased exponentially following the equation: pokes required = $\left[5 e^{\text {(injection number } \times 0.2)}\right]-5$ (Richardson and Roberts, 1996). CS and DS were presented during this session. The session lasted a maximum of $5 \mathrm{~h}$ with the session ending $1 \mathrm{~h}$ after the last reward if the next ratio was not reached. The breakpoint value was defined as the number of pokes performed to earn the last cocaine infusion obtained by the animal.

Extinction sessions. Performed only in mice that met criteria for cocaine self-administration behavior acquisition (see above) and had a patent catheter on the day of the progressive responding session. During extinction, cocaine was replaced with saline. Daily sessions lasted $2 \mathrm{~h}$ and mice were run 5 days a week. In cues-ON extinction, pokes in the active hole resulted in delivery of a saline infusion instead of cocaine. CS and DS lights were presented as during training sessions. In cues-OFF extinction, pokes in the active hole resulted in delivery of a saline infusion and the CS and DS lights were not presented.

Cue-induced reinstatement session. Animals were run in a single $2 \mathrm{~h}$ reinstatement session following 15 cues-OFF extinction sessions. In the reinstatement session, each active nose-poke resulted in a saline infusion. CS and DS were presented as described during training.

Stimulus light sessions. Naive animals that had not undergone surgery were placed in $2 \mathrm{~h}$ sessions and received no reward. Nose-pokes in the right hole resulted in presentation of the CS and the DS was also presented as described during training for cocaine self-administration.

\section{Operant Sucrose Self-Administration}

This operant behavior with food reinforcer experiment was performed using male mice (age $=77.7 \pm 7.8$ days) in the same operant chambers (slightly modified) and as similar as possible to the operant behavior with cocaine reinforcer experiment. Mice were food restricted to $90 \%$ of baseline body weight for the duration of the training starting 2 days before the first training session. Because of the requirement for food restriction, it was not appropriate to match more 
closely the age of mice used for sucrose with those used for cocaine experiments. Using animals under 8 weeks of age, which are still growing and do not show stable body weight, would create uncertainty in the level of food restriction that in turn would cause undesired fluctuations in the motivation to obtain food reward.

Training. Operant-naive mice were trained on FR1 schedule to earn sucrose ( $50 \mu \mathrm{l}, 10 \%$, w/v sucrose solution) during daily $2 \mathrm{~h}$ long sessions for 5 days a week. Pokes in the active nose-poke hole resulted in the delivery of sucrose into the food receptacle. The DS and CS were presented as described during training for cocaine self-administration. Head entries into the food receptacle were recorded and the receptacle was checked after every session to confirm that sucrose was consumed. The maximum number of rewards per session was $120(6 \mathrm{ml})$. Criteria for acquisition were set as $\geq 30$ rewards per session and a 3:1 ratio of active to inactive pokes for 4 consecutive sessions. Access to food in the home cage was restricted to $\sim 2 \mathrm{~g}$ chow/mouse/day and it was adjusted as to not exceed $20 \%$ loss from initial body weight. Restriction started 1-2 days before training began and lasted for the duration of the experiment.

Cue-ON extinction sessions. These were identical to training sessions, except that sucrose was not delivered upon responding in the active nose poke hole. CS and DS were presented as described during training sessions.

\section{Experimental Design}

Experiments $A$ and $B$. Surgery was performed on 75 mice (38 Drd2 ${ }^{\text {loxP/loxP }}$ and 37 autoDrd2KO); 89\% survived surgery and recovery (33/38 Drd2 loxP/loxP and 34/37 autoDrd2KO). Of the surviving mice, $80 \%$ completed training with patent catheters and were used in data analysis $\left(29 / 33\right.$ Drd2 $2^{\text {loxP/loxP }}$ and 25/34 autoDrd2KO). Mice were run in cohorts of 8-15 mice with both genotypes running in parallel in 8 operant behavioral boxes. AutoDrd2KO mice and $\operatorname{Drd} 2^{\text {loxP } / \text { loxP }}$ wildtype littermates were run simultaneously in 15 training sessions followed by a single progressive responding session and 15 extinction sessions (Table 1). In experiment $A, 12$ $\operatorname{Drd} 2^{\text {loxP } / \text { loxP }}$ and 13 autoDrd2KO mice underwent cues-OFF extinction sessions followed by a single cue-induced reinstatement session 1-3 days after the last cues-OFF extinction session. In experiment $B, 10$ mice of each genotype underwent cues-ON extinction sessions. Three mice $\left(1 \operatorname{Drd} 2^{\text {loxP } / l o x P}\right.$ and 2 autoDrd2KO) were run in training followed by extinction sessions with no progressive responding session.

Experiment $C$. Surgery was performed on 15 mice (7 $\operatorname{Drd} 2^{\text {loxP/loxP }}$ and 8 autoDrd2KO) in 2 independent cohorts. Six mice from each genotype (75-85\%) completed the experiment with patent catheters and were used in data analysis. Before the dose-response sessions, animals were trained according to the procedure described in the training section until the acquisition criteria were met and responding was stable (9-12 sessions). Then, animals received two consecutive sessions with access to the following doses of cocaine in this order (in mg/kg): 1, 0.1, 0.01, 0.032, 0.32, and
3.2. Responding for each cocaine dose was averaged per animal. The CS and DS were presented as described for the training sessions.

Experiment D. Thirteen mice $\left(\begin{array}{lll}6 & D r d 2^{\operatorname{lox} P / l o x P}\end{array}\right.$ and 7 autoDrd2KO) were run in 6 consecutive stimulus light sessions to examine responding for stimulus lights not paired with cocaine. Similar to cocaine self-administration training, sessions lasted for $2 \mathrm{~h}$ with the exception of the first three sessions that were for $6 \mathrm{~h}$. Naive stimulus preference was measured as the ratio of pokes in the right nose-poke hole (paired with CS/stimulus lights) vs pokes in left nose-poke hole (no CS/stimulus lights).

Experiment E. Twenty-three mice (10 Drd2 $2^{\text {loxP } / l o x P}$ and 13 autoDrd2KO) were trained in the operant boxes to poke for $10 \%$ sucrose solution as reinforcer. AutoDrd2KO mice and $\operatorname{Drd2} 2^{\text {loxP/loxP }}$ wild-type littermates were run simultaneously in 15 training sessions, followed by 15 cues-ON extinction sessions (Table 1). During the extinction session, the CS and DS cue lights were on as in the training sessions, and only the delivery of the reinforcer was disabled.

\section{Statistical Analysis}

Statistical analysis was performed in Prism (GraphPad). Unpaired two-tailed Student's $t$-test was used for all binary comparisons unless stated. Two-way repeated measures ANOVA (2W-RM-ANOVA) was used when appropriate and followed by Tukey's multiple comparison analysis (Bonferroni was used in few occasion, when appropriate). One-way ANOVA and Kolmogorov-Smirnov (KS) and Fisher's exact test were also used when stated. All error bars in the figures represent SEM.

\section{Drugs}

Cocaine[HCl] (1 mg/kg i.p.; $10 \mu \mathrm{M}$ in vitro bath application) was obtained from the National Institute on Drug Abuse (NIDA) and dissolved in saline. Heparin[Na] $(100 \mathrm{U} / \mathrm{ml})$, Ketamine[HCl] $(1.5 \mathrm{mg} / \mathrm{kg})$, and Midazolam[HCl] $(0.75 \mathrm{mg} /$ $\mathrm{ml}$ ) were obtained through the NIH Office of Research Services, Division of Veterinary Resources (DVR), Veterinary Medicine Branch (VMB). The antibiotic trimethoprim sulfamethoxazole $(0.72 \mathrm{mg} / \mathrm{ml}$ in drinking water $)$ was obtained by the Animal Facility from Hi-TechPharma. Quinpirole[ $\mathrm{HCl}](1 \mu \mathrm{M}$ in vitro; Q102) was obtained from Sigma-Aldrich and sulpiride $(1 \mu \mathrm{M}$ in vitro; 0894$)$ from Tocris.

\section{RESULTS}

\section{Absence of D2R-Mediated Inhibition of DA Release in AutoDrd2KO Mice}

Electrical stimulation has been the classical method used to evoke DA release and study DA transmission in vitro. However, electrically evoked DA transients recorded in vitro are subject to nicotinic and muscarinic modulation (Zhang et al, 2002; Zhou et al, 2001) that is now known to be because of simultaneous activation of local cholinergic interneurons within the striatum. Direct stimulation of 
Table I Summary of the Experimental Design for the Five Experiments A through E

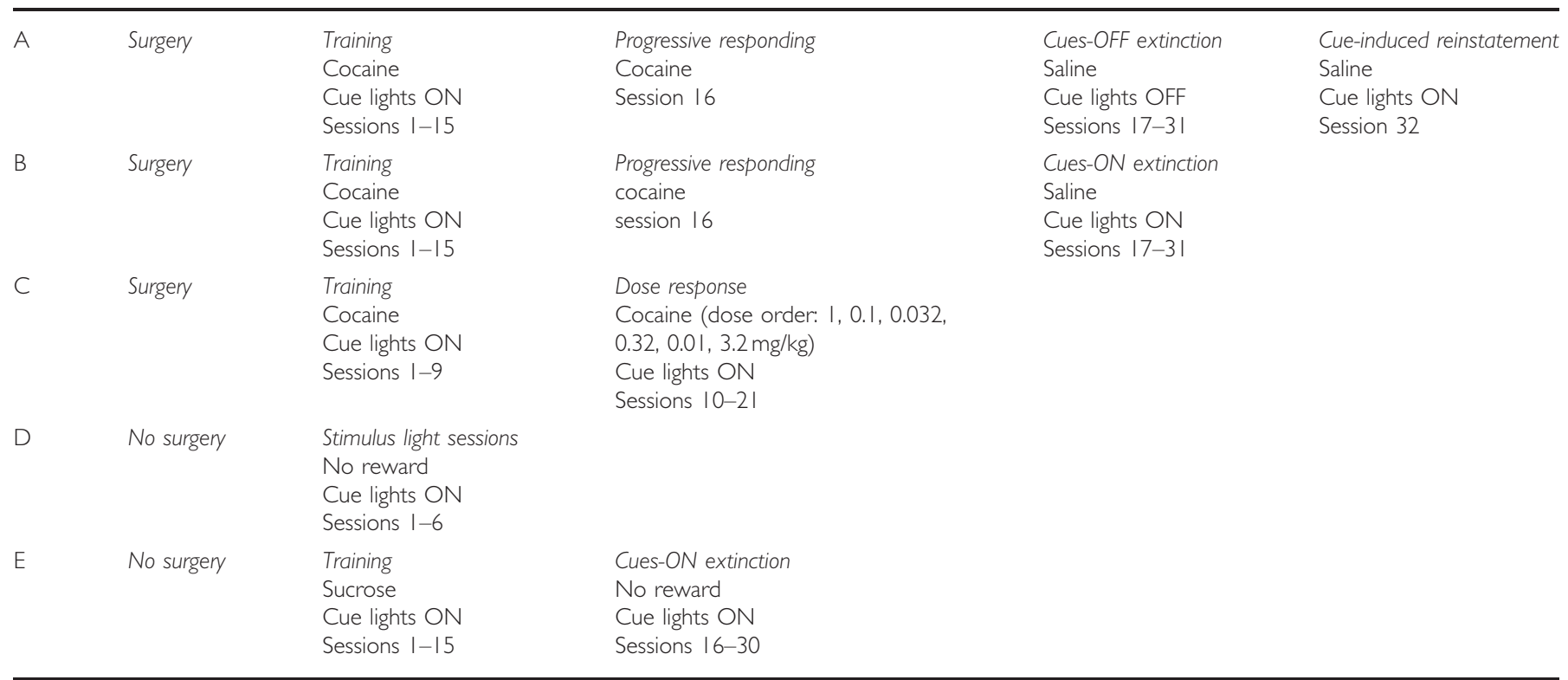

these cholinergic interneurons is sufficient to evoke DA release via activation of nicotinic receptors in DA terminals (Cachope et al, 2012; Threlfell et al, 2012). Thus, this study uses optogenetic stimulation to selectively activate DA fibers and bypass this cholinergic modulation. This is particularly important because cholinergic interneurons also express D2Rs (Alcantara et al, 2003) and D2-like agonists can inhibit acetylcholine release in the striatum in vivo (Bertorelli and Consolo, 1990) that can create interference between D2R modulation of Ach and DA transmission when using electrical stimulation. Thus, by directly activating DA fibers, these experiments will allow us to isolate D2R modulation of DA transmission in the NAc mediated by D2 autoreceptors expressed in midbrain DA neurons.

Electrical and optogenetic stimulations were delivered alternatively in the same slice to evoke DA transients recorded using FSCV in autoDrd2KO and control $D A T^{+/ I R E S-C R E}$ mice expressing ChR2-EYFP in midbrain DA neurons (Figure 1e). DA transients evoked by optogenetic stimulation (oDA) had identical voltammograms to DA transients evoked by electrical stimulation (eDA) and displayed the electrochemical fingerprint of DA (Figure 1f), in agreement with our recent study (Adrover et al, 2014). The amplitudes of oDA and eDA transients were similar in both genotypes under these conditions $(207 \pm 31$ vs $221 \pm 31 \mathrm{nM}, n=10$ slices $/ 4$ mice for oDA and eDA in autoDrd2KO, respectively; $196 \pm 15$ vs $226 \pm 20 \mathrm{nM}, n=16$ slices/7 mice for oDA and eDA control, respectively; no significant effects $F s<0.83$, $p s>0.37$, Figure 1f and g). Furthermore, the kinetics of the DA concentration transients were similar between genotypes, consistent with reported values for DA clearance in $\operatorname{Drd} 2^{\operatorname{lox} P / l o x P}$ mice, suggesting that DAT function is normal in heterozygous $D A T^{+/ I R E S-C R E}$ and autoDrd2KO mice (Bello et al, 2011; Good et al, 2011).

The loss of functional D2 autoreceptors in DA terminals of autoDrd2KO mice was confirmed by testing the effect of the D2-like agonist quinpirole on DA transmission. Although in control $D A T^{+/ I R E S-C R E}$ mice, quinpirole $(1 \mu \mathrm{M})$ inhibited oDA transients by $76.5 \pm 1.7 \%$ ( $n=5$ slices $/ 3$ mice, Adrover, et al, 2014), this maximal concentration of quinpirole had no effect on oDA transients in autoDrd2KO mice ( $110.1 \pm 1.2 \%$ of baseline after quinpirole, $n=7$ slices/ 3 mice; Figure $1 \mathrm{~h}$ and i). In summary, autoDrd2KO mice lack functional D2Rs in the terminals of DA neurons projecting to the NAc that normally mediate feedback inhibition of DA release.

\section{Loss of Inhibitory Feedback Amplifies In Vitro Cocaine Response}

Cocaine $(10 \mu \mathrm{M})$ prolonged oDA transients and increased the decay time from $0.45 \pm 0.04$ to $2.7 \pm 0.2 \mathrm{~s}$ in control mice and from $0.44 \pm 0.04$ to $2.9 \pm 0.2 \mathrm{~s}$ in autoDrd2KO $(n=7-10$ slices/3-4 mice, 2W-ANOVA interaction $\mathrm{F}(2,19)=0.2953$, $p=0.75$, effect of cocaine $\mathrm{F}(1,19)=247.4, p<0.0001$ and genotype $\mathrm{F}(2,19)=0.1903, p=0.83$; Figure $2 \mathrm{~b})$. This high concentration of cocaine also increased the amplitude of oDA by $74.5 \pm 15 \%$ in autoDrd2KO mice but it showed no significant effect in control mice $(1 \pm 9 \%$, one-way ANOVA $\mathrm{F}(2,24)=14.8, p<0.0001$, Tukey's multiple comparison: autoDrd2KO vs DAT $T^{+/ I R E S-C R E} p=0.0004, D A T^{+/ I R E S-C R E}$ vs $D A T^{+/ I R E S-C R E}+$ sulpiride $p=0.0002$, autoDrd2KO vs $D A T^{+/ I R E S-C R E} p=0.94$; Figure $2 \mathrm{c}$ ). We recently showed evidence that this concentration of cocaine causes sufficient accumulation of extracellular DA to engage presynaptic D2 autoreceptors and suppress release from DA terminals (Adrover et al, 2014). In the presence of the D2-like receptor antagonist sulpiride, cocaine increased oDA amplitude by $80 \pm 11 \%$ in control mice, and this was indistinguishable from the cocaine-induced enhancement of oDA amplitude in autoDrd2KO mice (Figure 2c). Thus, the presence of D2R antagonist mimicked the effect seen in autoDrd2KO mice, suggesting that mice lacking D2 autoreceptors show an 
a

control autoDrd2KO

control + sulpiride

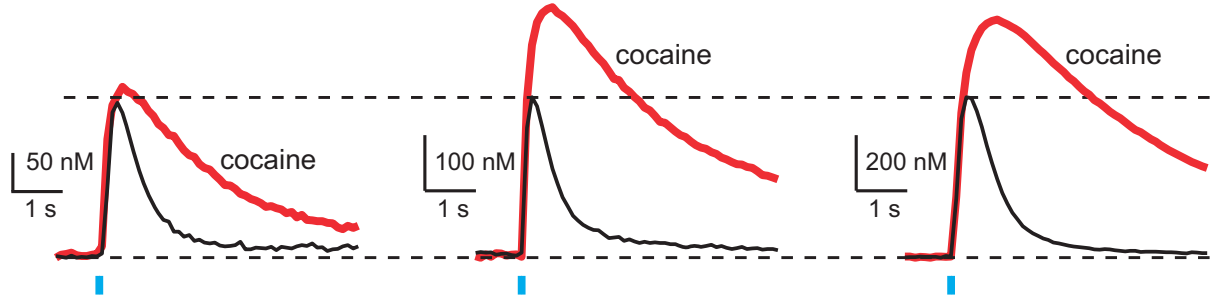

b

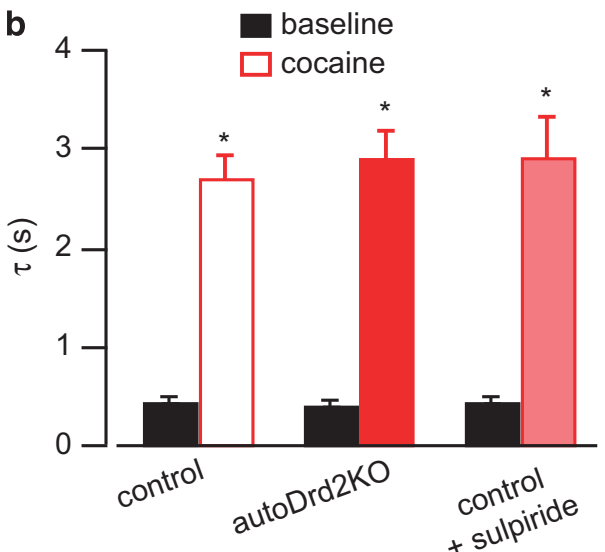

C

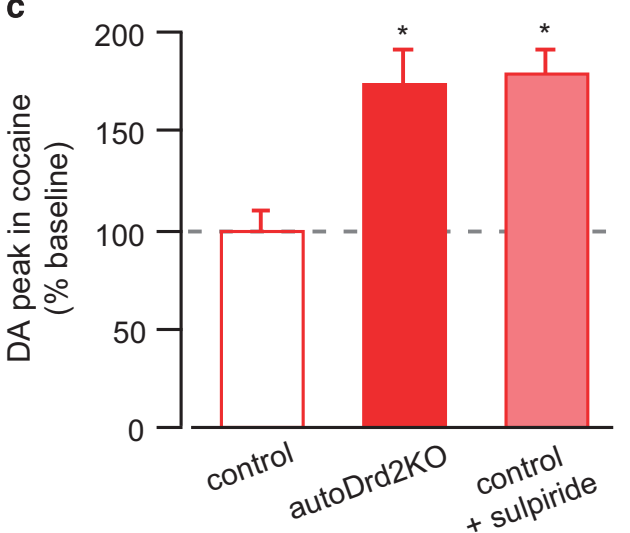

Figure 2 Augmented DA transients after cocaine in mice lacking D2 autoreceptors. (a) Representative oDA transients before (black) and after cocaine ( I $0 \mu \mathrm{M}$, red) in control, autoDrd2KO, and control mice in the presence of sulpiride. (b) Decay time constant $(\tau)$ of oDA transients before (black) and after cocaine (red) in control (open), autoDrd2KO (solid), and control mice in the presence of sulpiride (shaded). (c) Amplitude of oDA transients after cocaine expressed as percentage of baseline for control (open), autoDrd2KO mice (solid), and control mice in sulpiride (shaded). All data expressed as mean \pm SEM.

enhanced response to cocaine because of loss of feedback inhibition of DA release.

\section{Enhanced Acquisition of Cocaine Self-Administration in autoDrd2KO Mice}

We investigated whether a lack of D2 autoreceptors affected the reinforcing properties of cocaine in vivo. AutoDrd2KO mice and control littermates $\left(\operatorname{Drd} 2^{\text {loxP/loxP }}\right)$ were trained on a cued-operant task to self-administer cocaine intravenously over several weeks (Figure $3 \mathrm{a}$ and b). Mice were trained on a fixed ratio of 1 (FR1) schedule in which each poke in the active hole resulted in an intravenous cocaine infusion $(1 \mathrm{mg} / \mathrm{kg}$ ) paired with a cue light (experiments A and B, Table 1 in Materials and Methods). The criteria for acquisition were set as a minimum of 10 infusions/session and mean active/inactive poke ratio of $\geq 3$ for four consecutive sessions, similar to the criteria used by other studies of intravenous cocaine self-administration in rodents (Ruiz-Durantez et al, 2006; Schramm-Sapyta et al, 2006; Thomsen et al, 2005b, 2009b). Figure 3c shows that the percentage of autoDrd2KO mice that met criteria was different than littermate controls under these conditions (KS test, $p<0.005, n=20-24$ ). For control littermates, 53\% (13/24) reached acquisition criteria within the first 7 sessions and $75 \%(18 / 24)$ by session 15 , in agreement with previously described acquisition rates of operant cocaine self-administration for C57Bl/6 mice (Caine et al, 2007, 2012). In sharp contrast, $90 \%(18 / 20)$ of autoDrd2KO mice met acquisition criteria by session 7 and 95\% (19/20) by session 15 (Fisher's exact $p=0.02$ and 0.11 , respectively). The average number of sessions required to meet criteria was significantly shorter for autoDrd2KO mice than littermate controls $(4.4 \pm 0.8$ vs $8.6 \pm 1.1$ sessions for autoDrd2KO and $D r d 2^{\text {loxP } / \text { oxP }}$ mice, respectively, $p=0.006$, $n=20-24$; Figure 3d). Under the conditions tested here, autoDrd2KO mice acquire self-administration behavior for $1 \mathrm{mg} / \mathrm{kg}$ cocaine more quickly than their control siblings, suggesting that impaired feedback inhibition over DA release in the mesolimbic circuit may increase vulnerability for cocaine taking.

To investigate whether autoDrd2KO mice also acquire self-administration of a natural reward more quickly, mice were trained under similar conditions used for cocaine to earn sucrose (10\% solution) as a reinforcer paired with a cue light (experiment E). Under these conditions and mild caloric restriction (see Materials and Methods), the acquisition curves for sucrose were overlapping for both genotypes (KS $p=0.66$ ) and $85 \%$ of autoDrd2KO and $80 \%$ of control littermates acquired sucrose self-administration by session 7 and 92\% autoDrd2KO and 90\% controls acquired the behavior by session 15 (Fisher's exact $p=1$ ). AutoDrd2KO and control littermates required a similar number of sessions to meet criteria for sucrose $(5 \pm 1.2 v \mathrm{~s}$ $5.5 \pm 1.5$ sessions for autoDrd2KO and $\operatorname{Drd} 2^{\operatorname{loxP} / \text { loxP }}$ mice, respectively, $p=0.79, n=10-13$; Figure 3f). Note that in our previous study performed under conditions of extreme caloric restriction in which mice consume all daily food under operant conditions, there was a difference in breakpoint for food reward (Bello et al, 2011). However, when 
a

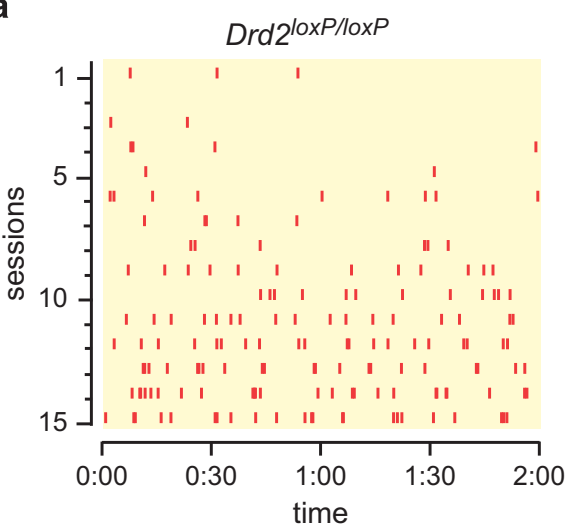

C

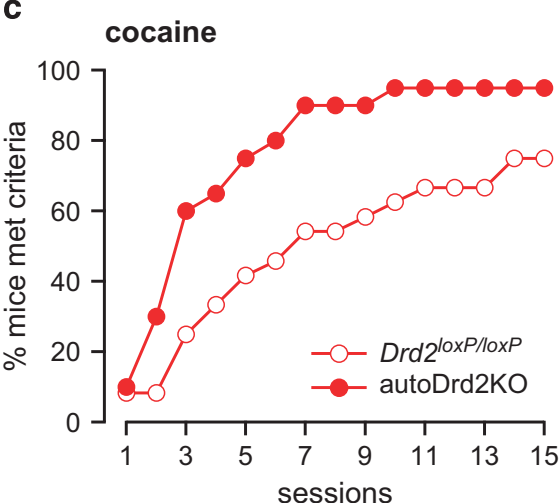

e

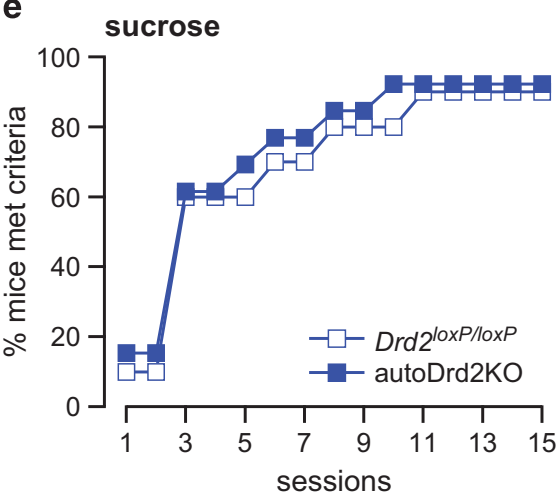

g

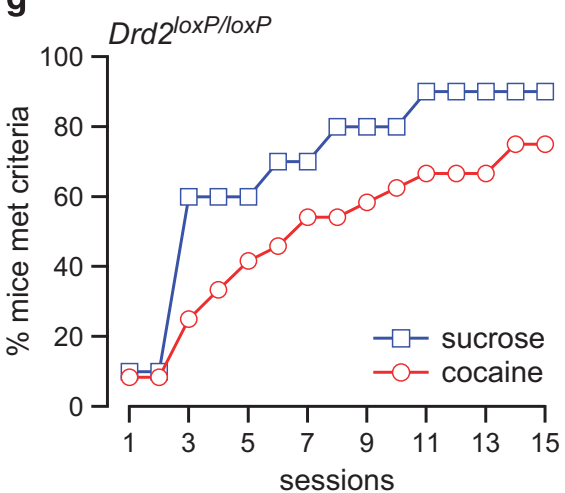

b

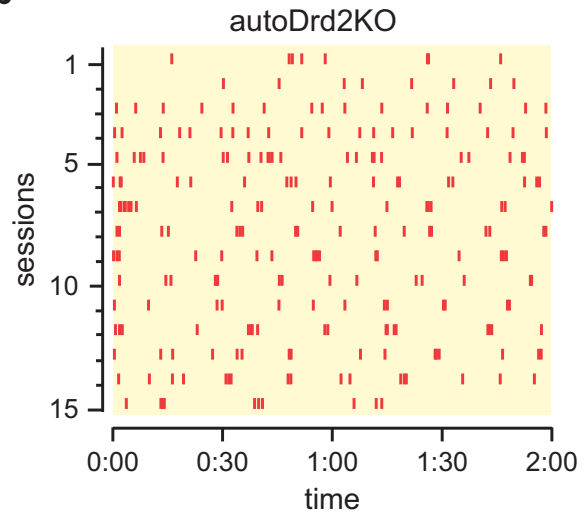

d

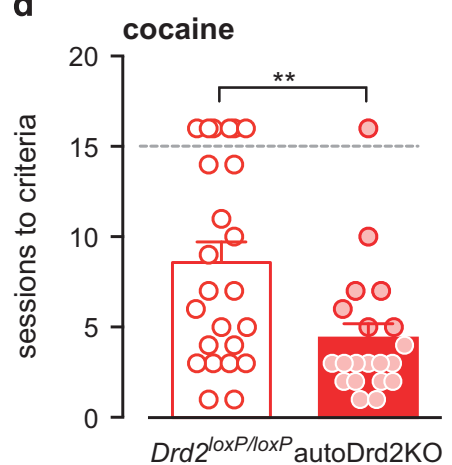

f

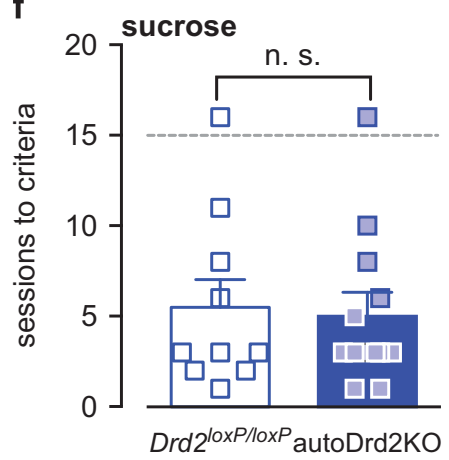

h

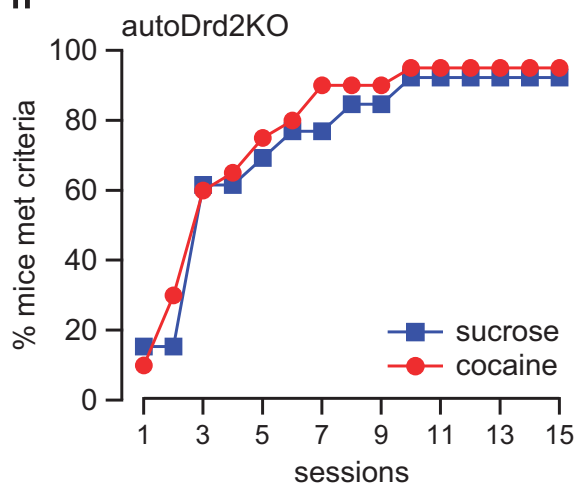


trained under mild caloric restriction and FR1 and other similar conditions of cocaine and sucrose, autoDrd2KO mice showed a selective predisposition to acquire selfadministration of a psychomotor stimulant but not a natural reward as compared with control littermates.

More detailed analysis indicated that the enhanced ability of autoDrd2KO mice to meet criteria for cocaine selfadministration at this dose $(1 \mathrm{mg} / \mathrm{kg})$ is driven by a combination of slightly higher numbers of earned cocaine infusions $\left(12.9 \pm 1.7 v s 9.5 \pm 1.6\right.$ for autoDr2KO and $\operatorname{Drd} 2^{\text {loxP/ }}$ ${ }^{l o x P}$; $2 \mathrm{~W}$-RM-ANOVA effect of interaction, genotype, and time $F s \geq 2.27$, $p s \leq 0.041$ ) and improved discrimination between active and inactive holes mainly during the first 7 sessions (Supplementary Figure 1A and B). Note that there were no statistical differences between the genotypes when analyzing these behaviors throughout the whole 15 training sessions or when considering the plateau phase (maintenance, sessions $8-15 ; 2$ W-RM-ANOVA, $F s \leq 1.23$, ps $\geq 0.26$ ). Contrarily, the same analysis of the sucrose selfadministration behavior revealed autoDrd2KO mice and control littermates earned similar numbers of sucrose rewards during the first seven training sessions and showed a similar degree of discrimination between active and inactive holes (Supplementary Figure 1C and D), explaining the lack of difference between the genotypes in the acquisition of sucrose self-administration behavior.

To summarize, the acquisition curves for cocaine and sucrose were compared for each genotype (Figure $3 g$ and $h$ ). Although the acquisition curves for sucrose and cocaine were significantly different for control $\operatorname{Drd} 2^{\text {loxP/loxP }}$ mice (KS, $p=0.0025)$, there were no differences between the curves for sucrose and cocaine for autoDrd2KO mice $(p=0.08)$. Thus, under conditions of mild food restriction, control mice showed an adaptive behavior in which they acquired sucrose more readily than cocaine. In contrast, mice lacking D2 autoreceptors showed maladaptive behavior and acquired cocaine similarly to a natural reward with caloric content that is essential for survival, highlighting the extent of the vulnerability to acquire cocaine self-administration behavior in these mice.

\section{Similar Intake, Motivation, and Sensitivity for Cocaine in Mice That Acquired}

In the remainder of the study, only mice that met acquisition criteria were used and analyzed ( $n=19$ autoDrd2KO and $18 \operatorname{Drd2} 2^{\text {loxP/loxP }}$. AutoDrd2KO mice that met acquisition criteria for cocaine showed a similar rate of earned cocaine infusions as their counterpart Drd2 loxP/loxP mice that met criteria throughout the 15 sessions (2W-RMANOVA, $\mathrm{F}(1,33)=0.022, p=0.88, n=19-18$; Figure $4 \mathrm{a})$.
Furthermore, mice from both genotypes reached similar plateaus on daily cocaine intake during the last three sessions $(21.1 \pm 1.4 \quad v s \quad 20.3 \pm 1.8$ for autoDr2KO and $\operatorname{Drd2} 2^{\text {loxP/loxP }}, \quad n=19-18, \quad p=0.44 ;$ Figure $4 \mathrm{a}$ and $\mathrm{b}$, Supplementary Figure 2).

Mice that met the acquisition criteria by session 15 were challenged in a progressive-ratio schedule session in which the number of active nose-pokes required to obtain an additional cocaine infusion increased exponentially (experiments $\mathrm{A}$ and $\mathrm{B}$ ). The breakpoint value (number of pokes performed to earn the last cocaine infusion) indicates the maximal effort exerted to obtain a reinforcer and is used as an index of motivation to obtain a reward (DerocheGamonet et al, 2004; Richardson and Roberts, 1996). AutoDrd2KO mice and control littermates displayed similar breakpoint values for cocaine, suggesting no change in the motivational salience of cocaine $(43 \pm 9$ vs $36 \pm 8$ for autoDrd2KO and $\operatorname{Drd} 2^{\text {loxp } / \text { loxP }}$, respectively, $n=17-17$, $p=0.59$; Figure $4 \mathrm{c}$ ). The distributions of breakpoint values were very similar for each genotype (Figure 4d). Furthermore, the number of active pokes performed during the progressive-ratio schedule session was similar between genotypes $(216 \pm 52$ vs $183 \pm 47$ pokes for autoDrd2KO and $\operatorname{Drd2} 2^{\text {loxp } / l o x P}$, respectively, $\quad n=17-17, \quad p=0.64$; Figure 4e).

AutoDrd2KO mice were previously shown to be hypersensitive to the acute psychomotor and rewarding properties of cocaine (Bello et al, 2011). We speculated that a leftward shift in the dose-response curve for cocaine selfadministration could also explain the faster acquisition rate of autoDrd2KO mice. Therefore, we measured responding for varying doses of cocaine $(0.01$ to $3.2 \mathrm{mg} / \mathrm{kg})$ following acquisition of cocaine self-administration behavior in a subset of mice that met acquisition criteria (experiment $\mathrm{C}$ ). The dose-response curves showed a typical inverted $U$ shape and were overlapping for both genotypes under the conditions tested here $(n=6-6$; Figure $4 \mathrm{f})$. Taken together, we show that although autoDrd2KO mice acquired cocaine self-administration behavior more quickly, after behavior acquisition they did not differ from littermate controls in daily intake, motivation, or sensitivity for cocaine.

\section{Enhanced Reactivity to Cocaine-Paired Cues}

The ability to extinguish cocaine self-administration behavior was tested either in the presence of or in the absence of the drug-paired cue lights (DS and CS) in mice that met acquisition criteria. During cues-ON extinction, cocaine was replaced with saline and cue lights previously paired with cocaine were turned on upon responding in the active hole (experiment B, Figure 1a and b). During cues-OFF

Figure 3 Enhanced acquisition of cue-paired intravenous cocaine self-administration in autoDrd2KO mice. (a, b) Representative responding of a

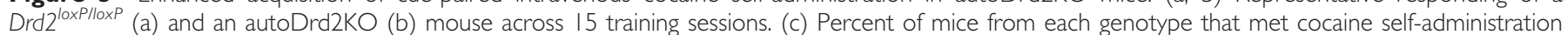

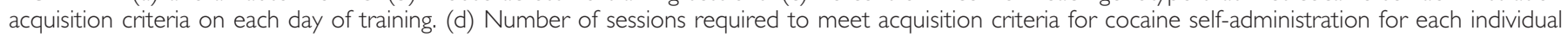

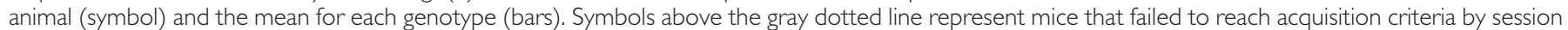

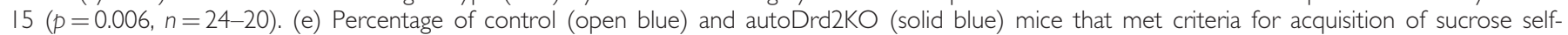
administration throughout the sessions $(n=10-13)$. ( $f$ ) Number of sessions required to meet acquisition criteria for sucrose self-administration for each

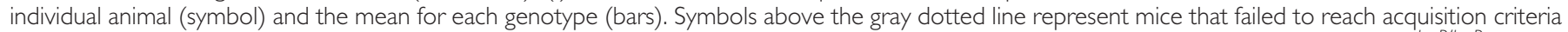

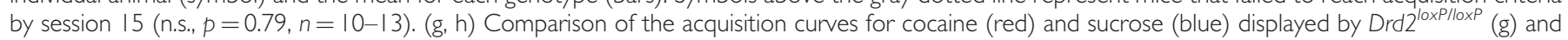
autoDrd2KO (h) mice. Reported error is SEM. 
a

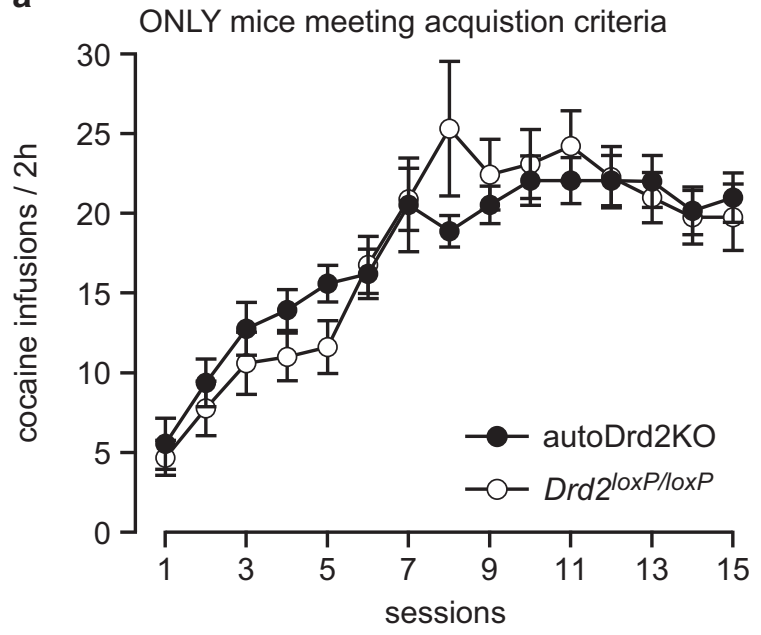

b

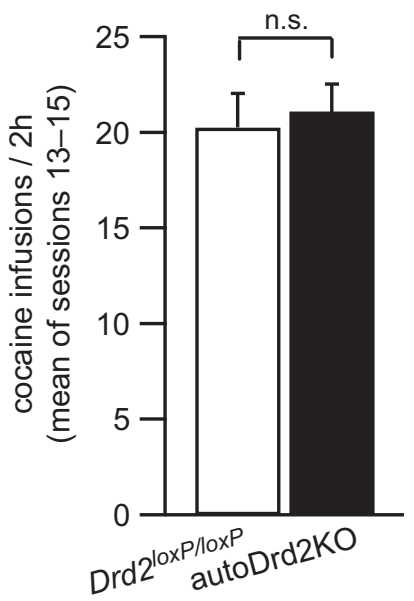

C

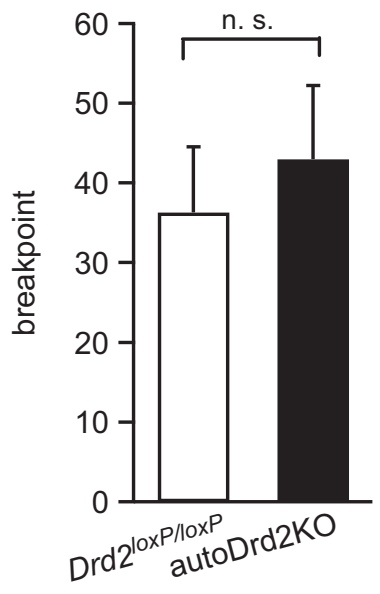

e

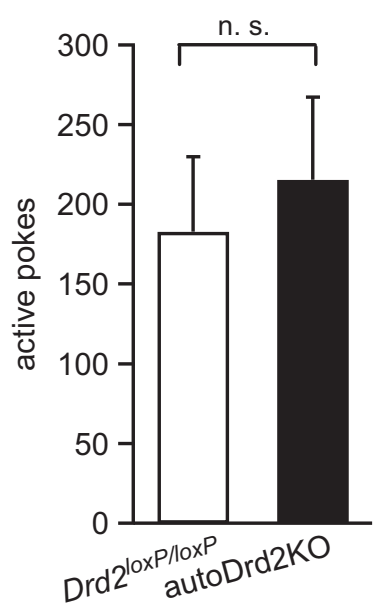

d

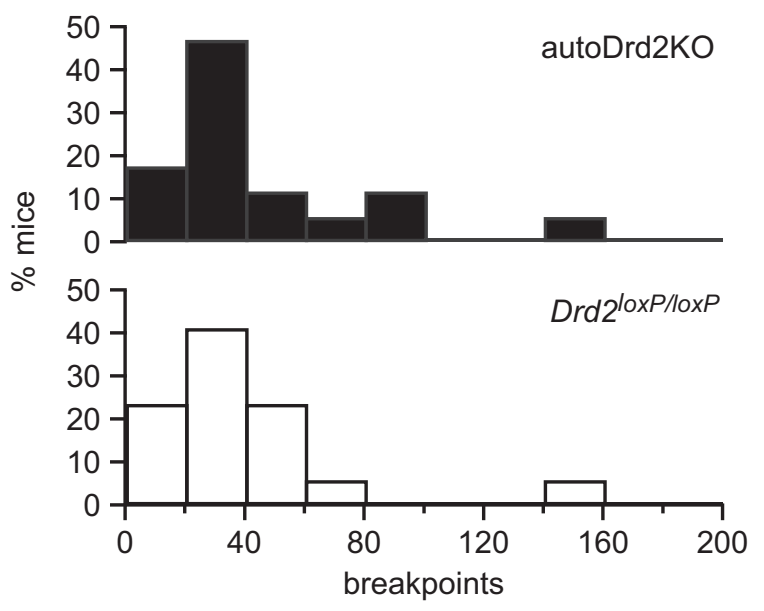

f

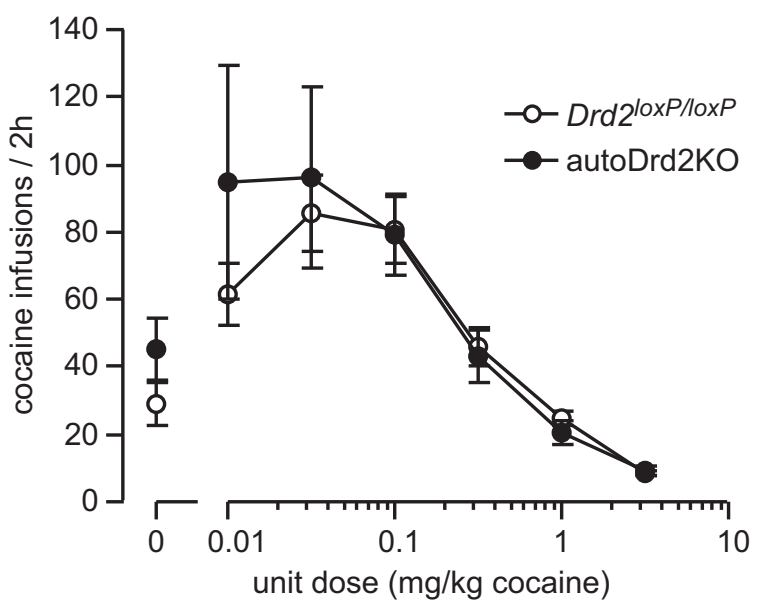

Figure 4 Once mice acquire, autoDrd2KO mice show similar daily intake, sensitivity, and breakpoint for cocaine. (a) Rate of earned cocaine infusions for autoDrd2KO (solid) and Drd2 ${ }^{\text {loxP/loxP }}$ (open) mice that met acquisition criteria. (b) Daily cocaine intake during the last 3 training sessions (sessions I3- 15 ) before extinction sessions for all mice that met acquisition criteria; n.s., not significant difference $p=0.44$. (c) Mean breakpoint value achieved during progressive-ratio session for autoDrd2KO (solid) and Drd2 loxP/loxP littermates (open); n.s., not significant difference $p=0.59, n=17-17$. (d) Distribution of breakpoint values for autoDrd2KO (top, solid) and Drd2 ${ }^{\text {loxPlloxP }}$ littermate (bottom, open) mice achieved during the progressive-ratio session. (e) Mean number of active pokes performed during progressive-ratio session for autoDrd2KO (solid) and Drd ${ }^{\text {loxPlloxP }}$ littermates (open); n.s., difference $p=0.64$, $n=17-17$. (f) Rate of cocaine infusions earned by autoDrd2KO (solid) and Drd ${ }^{\text {loxP/loxP }}$ littermate (open) mice when varying the unitary dose of cocaine infusion; $n=6-6$. All data, except for (d), are expressed as mean \pm SEM. 
extinction, cocaine was replaced by saline and cue lights remained off upon responding in the active hole (experiment A). When cocaine-paired cue lights were presented during extinction sessions, autoDrd2KO mice showed a higher rate of responding than their littermate $\operatorname{Drd} 2^{\text {loxP/loxP }}$ mice throughout the 15 extinction sessions (2W-ANOVA, main effect of reinstatement: $F(1,42)=8.09, p=0.007$, Tukey's test autoDrd2KO: extinction $v s$ reinstatement $p<0.05 ; \operatorname{Drd} 2^{\operatorname{loxP} / l o x P}$ : extinction $v s$ reinstatement $p>0.05$; $n=13-10$; Figure $5 \mathrm{c}$ ). Furthermore, autoDrd2KO mice maintained a high response rate throughout the cue-ON extinction session in contrast to the declining rate of responding shown by $\operatorname{Drd} 2^{\text {loxP/loxP }}$ mice (Supplementary Figure 3A, 2W-RM-ANOVA: interaction $\mathrm{F}(23,345)=2388$, $p=0.0004$ )

When cue lights were not presented upon responding in the active hole, both genotypes showed a similar reduction in responding over the course of the session (Supplementary Figure 3B, 2W-RM-ANOVA: no interaction $\mathrm{F}(23,345)=1.041, \quad p=0.41)$. The rate of responding dropped sharply during the first 5 cue-OFF sessions and both genotypes reached a similar plateau during the last 5 cues-OFF sessions $(9.9 \pm 2.2 v s 7.4 \pm 1.4$ infusions $/ 2 \mathrm{~h}$ for autoDrd2KO and $\operatorname{Drd2} 2^{\text {loxP/loxP }}$, respectively, $n=13-10$ ). Thus, throughout the 15 cues-OFF sessions, autoDrd2KO mice showed similar extinction behavior as control littermates (2W-RM-ANOVA no effect of genotype: $\mathrm{F}(1,20)=1.78, p=0.2, n=13-10$; Figure $5 \mathrm{~d})$.

Further evidence of enhanced cue reactivity in autoDrd2KO mice was observed during a cue-induced reinstatement session when the cue lights previously paired with cocaine were reintroduced to mice that underwent cues-OFF extinction (experiment A). AutoDrd2KO mice that behaved similarly to control littermates during cues-OFF extinction showed a higher rate of responding in the active hole during cue-induced reinstatement sessions compared with $\operatorname{Drd} 2^{\text {loxP/loxP }}$ mice, despite the absence of cocaine delivery (25.2 \pm 6.8 vs $13 \pm 3.6$ infusions/2 $\mathrm{h}$ for autoDrd2KO and $\operatorname{Drd} 2^{\text {loxp }}$ /loxP , respectively, main interaction genotype $\times$ reinstatement $\quad \mathrm{F}(1,39)=4.5, \quad p=0.04, \quad n=10-13$; Figure 5e). This result further confirms the enhanced reactivity to cocaine-paired cues in autoDrd2 $\mathrm{KO}$ mice.

Cues-ON extinction of natural reward seeking was also assessed. Mice that met acquisition criteria for sucrose selfadministration were tested in 15 cues-ON extinction sessions (experiment E). During these sessions, sucrose was replaced with saline and formerly sucrose-paired cue lights (DS and CS) were turned on upon responding in the active nose-poke hole. AutoDrd2KO mice showed similar responding compared with control littermates across 15 sessions of cues-ON sucrose extinction (2W-RM-ANOVA, no effect of genotype: $\mathrm{F}(1,13)=0.082, p=0.78, n=7-10$; Figure 5f). Thus, mice lacking the D2 autoreceptor showed a selective enhancement in the salience of cocaine-paired cues but not sucrose-paired cues.

Furthermore, we assessed the possibility that autoDrd2KO mice are merely more reactive to novel cues. Drug-naive autoDrd2KO mice showed similar responding rates as control littermates for stimulus lights that were never paired with cocaine (experiment D, 2W-RM-ANOVA Fs $\leq 2.32$, $p$ s $\geq 0.056, n=7-6$, Supplementary Figure 4). Therefore, we conclude that autoDrd2KO mice are not simply more reactive to novel stimuli, but instead display a specific enhancement in the reactivity to cocaine-paired cues.

For a direct comparison of the different patterns of extinction seen for cocaine and sucrose in each genotype, each extinction curve was normalized to the average rate of intake of each mouse of the last 3 days before extinction and plotted together for $\operatorname{Drd} 2^{\text {loxP } / l o x P}$ and autoDrd2KO mice (Figure $5 \mathrm{~g}$ and $\mathrm{h}$ ). Control $\operatorname{Drd} 2^{\operatorname{loxP} / / 0 x P}$ mice showed a similar pattern of extinction under all conditions (2W-RMANOVA: no effect of reward/extinction type $\mathrm{F}(2,22)=4.1$, $p=0.03$; main effect of time $\mathrm{F}(9,198)=8.81, p<0.0001$ ). Interestingly, although cocaine extinction behavior for control $\operatorname{Drd2} 2^{\text {loxP/loxP }}$ mice was similar regardless of whether cues were present or not, extinction of sucrose selfadministration behavior was different during the first sessions $(2 \mathrm{~W}$-ANOVA time $\times$ reward/extinction interaction $\mathrm{F}(18,198)=1.706, p=0.041$, Tukey's test: day $1 \mathrm{ON} v s \mathrm{ON}$ $p<0.01)$. On the contrary, although autoDrd2KO mice demonstrated a normal ability to extinguish cocaine seeking in the absence of cues and sucrose seeking in the presence of food-paired cues, in the presence of cocaine-paired cues these mice display perseverative responding and fail to extinguish cocaine-seeking behavior (2W-RM-ANOVA, main effect of reward/extinction $\mathrm{F}(2,26)=6.16, p=0.007$; effect of time $\mathrm{F}(9,234)=2.84, p=0.003$; no interaction $\mathrm{F}(18,234)=0.66, p=0.85)$.

\section{DISCUSSION}

This study reveals an important role for D2 autoreceptors in regulating the acquisition of cocaine self-administration behavior and the reactivity to cocaine-predictive cues. Mice lacking D2 autoreceptors lose feedback inhibition over DA release and, as a result, cocaine induces an even greater increase in DA concentration in the NAc relative to control mice. AutoDrd2KO mice also acquire cued-operant selfadministration behavior for $1 \mathrm{mg} / \mathrm{kg}$ cocaine more quickly than control littermates. The overall cocaine intake of mice that acquired cocaine self-administration behavior $(95 \%$ for autoDrd2KO $v s \quad 80 \%$ for $\operatorname{Drd} 2^{\text {loxP } / l o x P}$ littermates met acquisition criteria) is similar across genotypes and so are the breakpoint values achieved during a progressive-ratio session and the dose dependence of cocaine self-administration behavior when tested under the conditions described here. Thus, although autoDrd2KO mice acquire cocaine self-administration behavior more quickly at the dose tested here, after acquisition they attribute similar motivational salience to the drug and display similar intake and satiety levels as $\operatorname{Drd} 2^{\text {loxP } / l o x P}$ littermates.

Importantly, this study also shows that autoDrd2KO mice, although capable of extinguishing cocaine selfadministration behavior in the absence of drug and cues, exhibit perseverative responding when cues previously paired with cocaine are present. AutoDrd2KO mice also show increased responding during cue-induced reinstatement. Therefore, we conclude that autoDrd2KO mice attribute enhanced incentive salience to cocaine-associated stimuli, accounting for the enhanced cue reactivity seen in cues-ON extinction and reinstatement. We speculate that autoDrd2KO mice exhibit increased sensitivity to the effect 


\section{a}

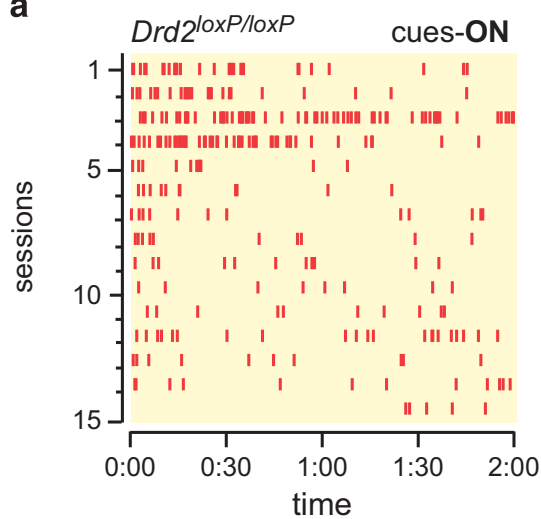

c

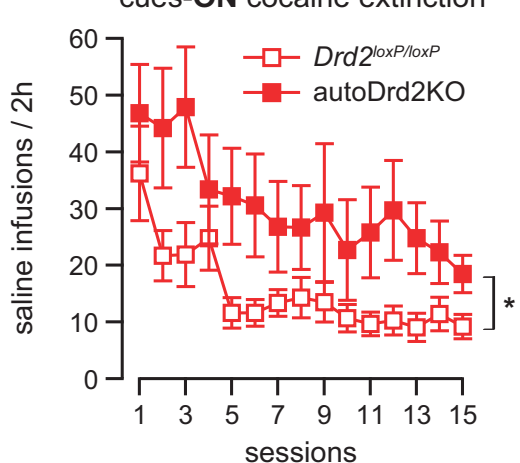

e $\square$ extinction - cues OFF ㅁ $\mathrm{c}$ cue reinstatement
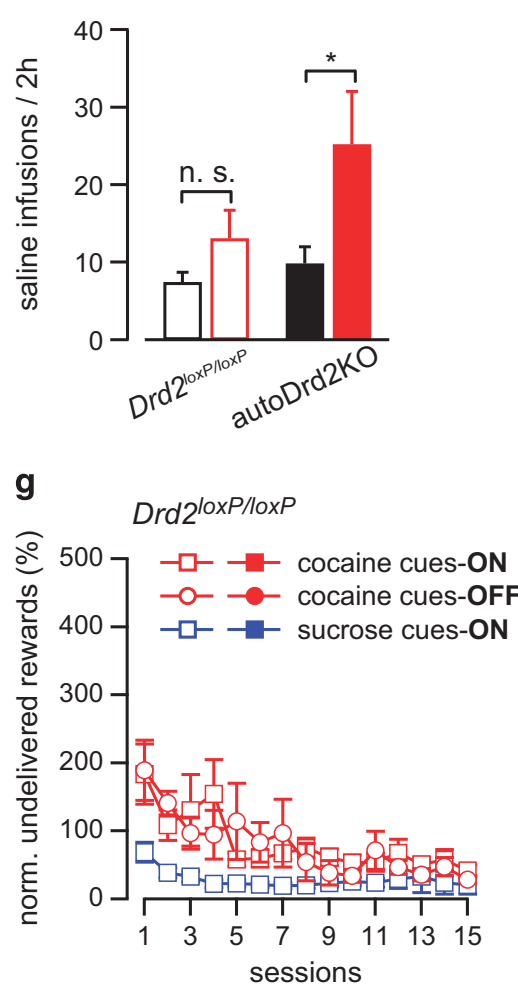

b

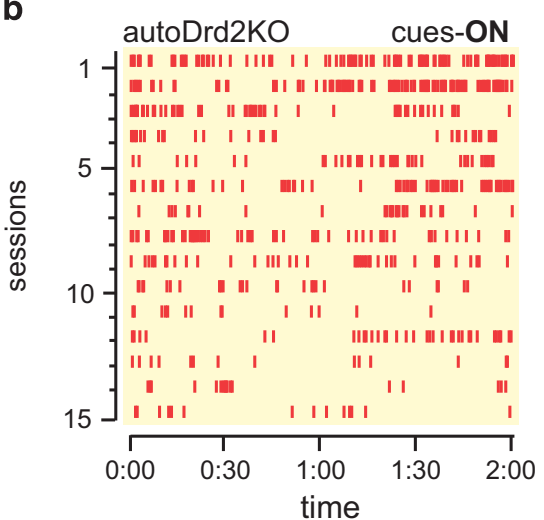

d

d cues-OFF cocaine extinction

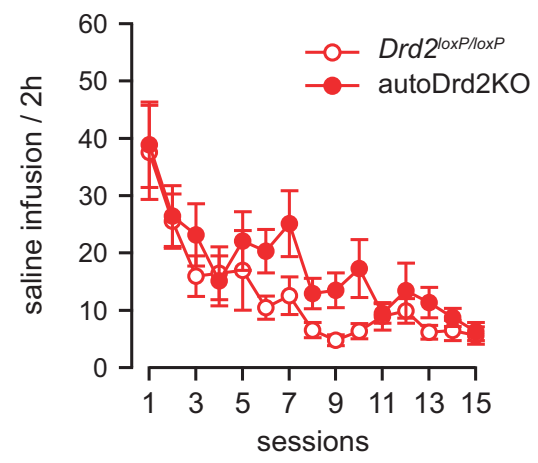

f

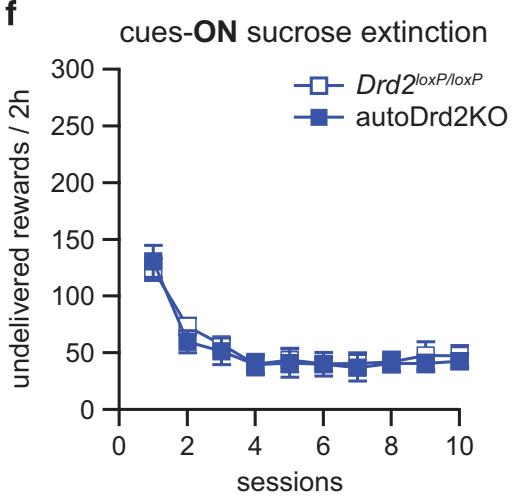

h

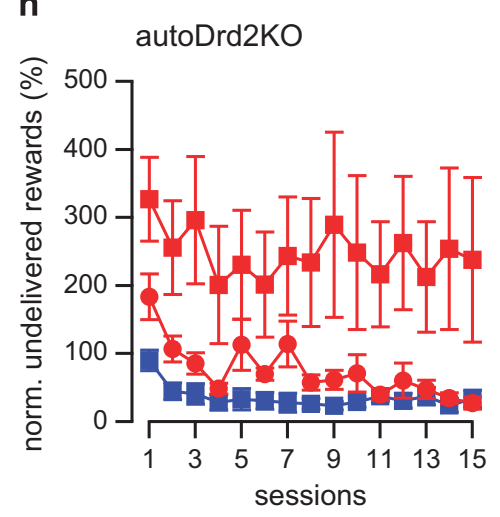


of the CS (cue light) on promoting learning that could explain the enhanced rate of acquisition (Deroche-Gamonet et al, 2002). This hypothesis can also explain the improved acquisition of cued-operant cocaine self-administration seen here, in which the CS and DS facilitate learning to a larger extent in autoDrd2KO, leading to the increased rate of acquisition for cocaine self-administration.

Under conditions similar to those used for operant cocaine self-administration ( $2 \mathrm{~h}$ daily sessions, FR1, pair of lights as CS and DS), the acquisition of self-administration behavior for a food reward such as $10 \%$ sucrose solution was similar between the genotypes. In addition, autoDrd2KO mice extinguished sucrose-seeking behavior like control littermates even when cues previously paired with sucrose were present. Thus, the propensity to engage in cocaine taking and the hyperreactivity to cues seen in autoDrd2KO mice are selective for stimulant drugs like cocaine. Although the reason for this selectively is still not completely understood, two not mutually exclusive explanations are presented here.

One possible explanation involves the loss of feedback inhibition over DA release and the enhanced acute response to cocaine seen in autoDrd2KO mice. The amplified acute cocaine effects seen in autoDrd2KO mice may provide a biological mechanism for the improved acquisition of drugtaking behaviors seen in these mice. This augmented cocaine effect was mimicked in control mice by blocking the feedback inhibition with a D2R antagonist, strongly suggesting that it is mediated by the lack of activation of D2 autoreceptors and in agreement with recent findings (Adrover et al, 2014). Cocaine prolongs DA transients by blocking DA reuptake and promotes the activation of presynaptic D2 autoreceptors that inhibit DA release in control Drd2 $2^{\text {loxP/loxP }}$ mice (Figure 2; Adrover et al, 2014). In autoDrd2KO mice, cocaine also blocks DA reuptake but does not promote activation of presynaptic D2 autoreceptors or inhibition of DA release and thus cocaine causes an even larger increase in DA transients in these mice. Natural rewards do not affect DA reuptake and they are not expected to prolong DA transients. As a consequence, we speculate that natural rewards are weaker than cocaine in promoting activation of presynaptic D2 autoreceptors and engaging the feedback inhibition over DA transmission. Under these conditions in which the feedback inhibition mechanisms are not engaged, autoDrd2KO and littermate $\operatorname{Drd} 2^{\text {loxP/loxP }}$ mice are similar. Thus, the response to natural rewards is similar between autoDrd2KO and littermate $\operatorname{Drd} 2^{\text {loxP/loxP }}$ mice under the conditions tested here.

Another explanation is that, because autoDrd2KO mice are hypersensitive to the psychomotor properties of cocaine (Bello et al, 2011), cocaine could increase locomotor activation, facilitate operant behavior, and create a positive feedback loop that is more pronounced in autoDrd2KO mice than controls. However, we found no differences in responding in the inactive nose-poke hole between autoDrd2KO mice and controls (Supplementary Figure 1B). Thus, it is unlikely that enhanced acquisition is due simply to an increase in locomotion, but instead is because of a higher sensitivity to the effect of the CS on promoting learning.

In Bello et al (2011), we showed that autoDrd2KO mice acquired CPP with a low dose of cocaine $(0.5 \mathrm{mg} / \mathrm{kg})$ to which control Drd $2^{\text {loxP/loxP }}$ littermate did not show CPP and we postulated that autoDrd2KO mice have a higher sensitivity to the rewarding properties of cocaine. In this study, however, we found that once autoDrd2KO mice acquired cocaine self-administration behavior, they show similar response rates for cocaine $(1 \mathrm{mg} / \mathrm{kg})$ and similar dose-dependent responding to cocaine as control $\operatorname{Drd} 2^{\operatorname{lox} P / \operatorname{lox} P}$ littermates. Thus, we conclude that the reinforcing properties of cocaine are not changed in autoDrd2KO mice. Although these new results could be seen as an apparent discrepancy, there are several methodological and theoretical explanations to consider. CPP and self-administration are not only behavioral paradigms that measure different aspects of a drug (reward $v s$ reinforcement, respectively), but these tests are also performed in different drug states. The reinforcing qualities assessed during self-administration here were determined with drug on board (drug state), whereas CPP was tested in a drug-free state. Thus, in the case of self-administration behavior, interoceptive cues and locomotor stimulation can also affect responding. Another important consideration is that the level of responding during self-administration can also be affected by the sensitivity to the rewarding properties of cocaine. If the reinforcing properties of cocaine are increased, enhanced sensitivity could lower responding and cancel out any increase in the responding rate because of enhanced reinforcement. Although this is a possible explanation for our results, we consider this to be unlikely given that we failed to detect a leftward shift in the dose-response curve to cocaine. The reasons for the lack of a leftward shift in the dose-response curve remain unclear; however, we consider this result additional evidence for distinctive neuronal mechanisms underlying the psychomotor, rewarding, and reinforcing properties of addictive drugs. Finally, there is an important learning component in the CPP test that involves learning the association of the drug-paired environment and the drug and it is possible that the enhanced cue reactivity shown by autoDrd2KO mice in our current study could result in faster learning of the association and account for the acquisition of low-dose cocaine CPP seen in Bello et al (2011).

Figure 5 Resistance to extinction in the presence of drug-paired cues and enhanced cue-induced reinstatement. (a, b) Representative raster plot showing

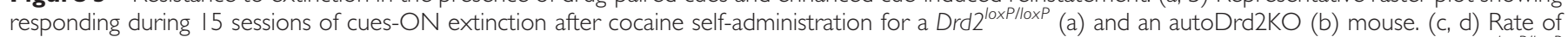

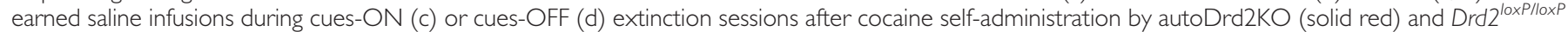

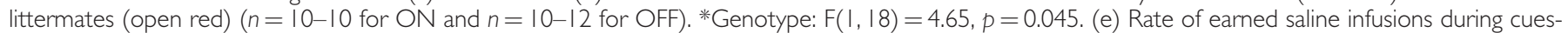

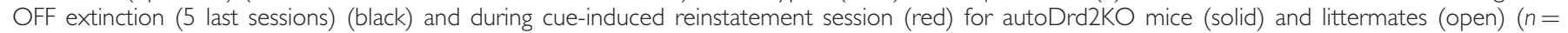
13-10). *2W-ANOVA $F(1,42)=8.09, p=0.007$, Tukey's $p<0.05$. (f) Rate of undelivered sucrose rewards during cues-ON extinction sessions after

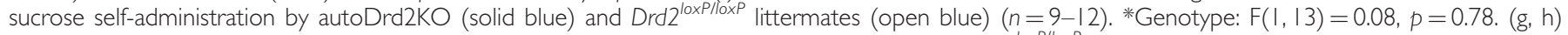

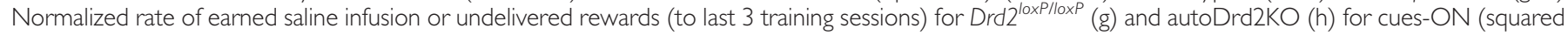
symbol, cocaine in red, sucrose in blue) and cues-OFF (cocaine in red, round symbol). Data expressed as mean \pm SEM. 
In a previous study, autoDrd2KO mice were trained on an operant self-administration task for food under different conditions as those used here (complete food deprivation, no CS and DS, and escalating responding schedule). We found that autoDrd2KO mice display higher breakpoint values for food under these conditions and show higher responding rates for food reward when working at a high fixed-ratio schedule (FR100), but not at lower fixed-ratio schedules (FR3, FR10, and FR30) (Bello et al, 2011). In the current study, mice were trained to self-administer sucrose under mild caloric restriction (90\% of the daily caloric needs were provided in home cage, with CS and DS, and under fixed ratio of 1 schedule (see experiment E). Breakpoint values for sucrose were not measured because this question is not within the scope of this study and it is very hard to speculate whether there would be a difference between the genotypes under the current conditions.

Hyperreactivity to drug-predictive cues is a feature displayed by addicts and an important trigger of relapse (Childress et al, 1993; Ehrman et al, 1992). Presentation of drug-paired cues to humans that abuse cocaine leads to increases in striatal DA levels and is sufficient to elicit craving (Volkow et al, 2006). Here we show that specific loss of D2 receptors expressed on nonstriatal neurons leads to an exaggerated acute response to cocaine and larger DA transients in the NAc. AutoDrd2KO mice show improved acquisition of cocaine self-administration, fail to extinguish cocaine seeking only in the presence of drug-paired cues, and show increased responding during cue-induced reinstatement. These effects were selective for cocaine and were not seen when mice were trained under similar conditions to earn a natural reward, providing critical evidence that the feedback inhibition mediated by D2 autoreceptors acts to limit the acquisition of cocaineseeking behavior and the incentive salience of rewardassociated cues. Furthermore, these findings show that selective manipulation of the D2 autoreceptor alone can cause phenotypic changes that resemble drug-related behaviors seen in human cocaine abusers.

\section{FUNDING AND DISCLOSURE}

The authors declare no conflict of interest. This study was funded by the Intramural Programs of NIAAA (VAA) and NINDS ZIA-AA000421 (to VAA), and by the ANPCYTMincyt of Argentina (to MR), Universidad de Buenos Aires (to MR), and Tourette Syndrome Association (to MR).

\section{ACKNOWLEDGEMENTS}

We thank Dr Ono for the use of confocal microscope. We are also grateful to Drs Dobbs and Lemos for their valuable comments on the manuscript. Dr K. Deisseroth generously provided the ChR2 constructs.

\section{REFERENCES}

Adrover MF, Shin JH, Alvarez VA (2014). Glutamate and dopamine transmission from midbrain dopamine neurons share similar release properties but are differentially affected by cocaine. The Journal of Neurosci 34: 3183-3192.
Alcantara AA, Chen V, Herring BE, Mendenhall JM, Berlanga ML (2003). Localization of dopamine D2 receptors on cholinergic interneurons of the dorsal striatum and nucleus accumbens of the rat. Brain Res 986: 22-29.

Belin D, Mar AC, Dalley JW, Robbins TW, Everitt BJ (2008). High impulsivity predicts the switch to compulsive cocaine-taking. Science 320: 1352-1355.

Bello EP, Mateo Y, Gelman DM, Noain D, Shin JH, Low MJ et al (2011). Cocaine supersensitivity and enhanced motivation for reward in mice lacking dopamine D2 autoreceptors. Nat Neurosci 14: 1033-1038.

Bertorelli R, Consolo S (1990). D1 and D2 dopaminergic regulation of acetylcholine release from striata of freely moving rats. J Neurochem 54: 2145-2148.

Besson M, Pelloux Y, Dilleen R, Theobald DE, Lyon A, Belin-Rauscent A et al (2013). Cocaine modulation of frontostriatal expression of Zif268, D2, and 5-HT2c receptors in high and low impulsive rats. Neuropsychopharmacology 38: 1963-1973.

Bock R, Shin JH, Kaplan AR, Dobi A, Markey E, Kramer PF et al (2013). Strengthening the accumbal indirect pathway promotes resilience to compulsive cocaine use. Nat Neurosci 16: 632-638.

Buckholtz JW, Treadway MT, Cowan RL, Woodward ND, Li R, Ansari MS et al (2010). Dopaminergic network differences in human impulsivity. Science 329: 532.

Cachope R, Mateo Y, Mathur BN, Irving J, Wang HL, Morales M et al (2012). Selective activation of cholinergic interneurons enhances accumbal phasic dopamine release: setting the tone for reward processing. Cell Rep 2: 33-41.

Caine SB, Negus SS, Mello NK, Patel S, Bristow L, Kulagowski J et al (2002). Role of dopamine D2-like receptors in cocaine selfadministration: studies with D2 receptor mutant mice and novel D2 receptor antagonists. J Neurosci 22: 2977-2988.

Caine SB, Thomsen M, Barrett AC, Collins GT, Grundt P, Newman AH et al (2012). Cocaine self-administration in dopamine $\mathrm{D}(3)$ receptor knockout mice. Exp Clin Psychopharmacol 20: 352-363.

Caine SB, Thomsen M, Gabriel KI, Berkowitz JS, Gold LH, Koob GF et al (2007). Lack of self-administration of cocaine in dopamine D1 receptor knock-out mice. J Neurosci 27: 13140-13150.

Childress AR, Hole AV, Ehrman RN, Robbins SJ, McLellan AT, O'Brien CP (1993). Cue reactivity and cue reactivity interventions in drug dependence. NIDA Res Monogr 137: 73-95.

Dalley JW, Fryer TD, Brichard L, Robinson ES, Theobald DE, Laane K et al (2007). Nucleus accumbens D2/3 receptors predict trait impulsivity and cocaine reinforcement. Science 315: 1267-1270.

Deroche-Gamonet V, Belin D, Piazza PV (2004). Evidence for addiction-like behavior in the rat. Science 305: 1014-1017.

Deroche-Gamonet V, Piat F, Le Moal M, Piazza PV (2002). Influence of cue-conditioning on acquisition, maintenance and relapse of cocaine intravenous self-administration. Eur J Neurosci 15: 1363-1370.

Ehrman RN, Robbins SJ, Childress AR, O’Brien CP (1992). Conditioned responses to cocaine-related stimuli in cocaine abuse patients. Psychopharmacology 107: 523-529.

Ford CP (2014). The role of D2-autoreceptors in regulating dopamine neuron activity and transmission. Neuroscience 28C: 13-22.

Franklin KBJ, Paxinos G (2007): The mouse brain in stereotaxic coordinates, 3rd Ed. Amsterdam: Elsevier.

Good CH, Hoffman AF, Hoffer BJ, Chefer VI, Shippenberg TS, Backman CM et al (2011). Impaired nigrostriatal function precedes behavioral deficits in a genetic mitochondrial model of Parkinson's disease. FASEB J 25: 1333-1344.

Madisen L, Zwingman TA, Sunkin SM, Oh SW, Zariwala HA, Gu H et al (2010). A robust and high-throughput Cre reporting and characterization system for the whole mouse brain. Nat Neurosci 13: 133-140.

Nader MA, Morgan D, Gage HD, Nader SH, Calhoun TL, Buchheimer $\mathrm{N}$ et al (2006). PET imaging of dopamine D2 
receptors during chronic cocaine self-administration in monkeys. Nat Neurosci 9: 1050-1056.

Rice ME, Patel JC, Cragg SJ (2011). Dopamine release in the basal ganglia. Neuroscience 198: 112-137.

Richardson NR, Roberts DC (1996). Progressive ratio schedules in drug self-administration studies in rats: a method to evaluate reinforcing efficacy. J Neurosci Methods 66: 1-11.

Ruiz-Durantez E, Hall SK, Steffen C, Self DW (2006). Enhanced acquisition of cocaine self-administration by increasing percentages of $\mathrm{C} 57 \mathrm{BL} / 6 \mathrm{~J}$ genes in mice with a nonpreferring outbred background. Psychopharmacology 186: 553-560.

Schramm-Sapyta NL, Olsen CM, Winder DG (2006). Cocaine selfadministration reduces excitatory responses in the mouse nucleus accumbens shell. Neuropsychopharmacology 31: 1444-1451.

Thomsen M, Caine SB (2005a). Chronic intravenous drug selfadministration in rats and mice. Curr Protoc Neurosci Chapter 9: Unit 9.20.

Thomsen M, Hall FS, Uhl GR, Caine SB (2009a). Dramatically decreased cocaine self-administration in dopamine but not serotonin transporter knock-out mice. J Neurosci 29: 1087-1092.

Thomsen M, Han DD, Gu HH, Caine SB (2009b). Lack of cocaine self-administration in mice expressing a cocaine-insensitive dopamine transporter. J Pharmacol Exp Ther 331: 204-211.

Thomsen M, Woldbye DP, Wörtwein G, Fink-Jensen A, Wess J, Caine SB (2005b). Reduced cocaine self-administration in muscarinic M5 acetylcholine receptor-deficient mice. J Neurosci 25: 8141-8149.

Threlfell S, Lalic T, Platt NJ, Jennings KA, Deisseroth K, Cragg SJ (2012). Striatal dopamine release is triggered by synchronized activity in cholinergic interneurons. Neuron 75: 58-64.

Volkow ND, Fowler JS, Wang GJ, Baler R, Telang F (2009). Imaging dopamine's role in drug abuse and addiction. Neuropharmacology 56 Suppl 1: 3-8.
Volkow ND, Wang GJ, Fowler JS (1997). Imaging studies of cocaine in the human brain and studies of the cocaine addict. Ann NY Acad Sci 820: 41-54 discussion 54-45.

Volkow ND, Wang GJ, Telang F, Fowler JS, Logan J, Childress AR et al (2006). Cocaine cues and dopamine in dorsal striatum: mechanism of craving in cocaine addiction. J Neurosci 26: 6583-6588.

Wong DF, Kuwabara H, Schretlen DJ, Bonson KR, Zhou Y, Nandi A et al (2006). Increased occupancy of dopamine receptors in human striatum during cue-elicited cocaine craving. Neuropsychopharmacology 31: 2716-2727.

Zald DH, Cowan RL, Riccardi P, Baldwin RM, Ansari MS, Li R et al (2008). Midbrain dopamine receptor availability is inversely associated with novelty-seeking traits in humans. J Neurosci 28: 14372-14378.

Zhang W, Yamada M, Gomeza J, Basile AS, Wess J (2002). Multiple muscarinic acetylcholine receptor subtypes modulate striatal dopamine release, as studied with M1-M5 muscarinic receptor knock-out mice. J Neurosci 22: 6347-6352.

Zhang Y, Svenningsson P, Picetti R, Schlussman SD, Nairn AC, Ho A et al (2006). Cocaine self-administration in mice is inversely related to phosphorylation at Thr34 (protein kinase A site) and Ser130 (kinase CK1 site) of DARPP-32. J Neurosci 26: 2645-2651.

Zhou FM, Liang Y, Dani JA (2001). Endogenous nicotinic cholinergic activity regulates dopamine release in the striatum. Nat Neurosci 4: 1224-1229.

(i) (2) This work is licensed under a Creative Commons Attribution-NonCommercial-ShareAlike 3.0 Unported License. To view a copy of this license, visit http:// creativecommons.org/licenses/by-nc-sa/3.0/

Supplementary Information accompanies the paper on the Neuropsychopharmacology website (http://www.nature.com/npp) 